\title{
Base promoted hydrogenolysis of lignin model compounds and organosolv lignin over metal catalysts in water
}

\author{
Hannelore Konnerth ${ }^{\mathrm{a}, \mathrm{b}}$, Jiaguang Zhang ${ }^{\mathrm{a}, \mathrm{c}}$, Ding Ma ${ }^{\mathrm{c}}$, Martin H.G. Prechtt ${ }^{\mathrm{b}, *}$, Ning Yan ${ }^{\mathrm{a}, * * *}$ \\ ${ }^{a}$ Department of Chemical and Biomolecular Engineering, National University of Singapore, 4 Engineering Drive 4, 117585, Singapore \\ ${ }^{\mathrm{b}}$ Department of Chemistry, Institute of Inorganic Chemistry, University of Cologne, Greinstraße 6, 50939 Cologne, Germany \\ ${ }^{\mathrm{c}}$ College of Chemistry \& Molecular Engineering, Peking University, 202 Chenfu Road, Beijing 100871, P. R. China
}

\section{H I G H L I G H T S}

- The first systematic study of base promotional effect in lignin hydrogenolysis..

- Lignin hydrogenolysis into aromatics was carried out in pure water under mild conditions.

- The yield for monomeric aromatic compounds from lignin increased ca. $100 \%$ in the presence of base.

- Base promotional effect was observed over Ru (a typical noble metal) and Ni (a typical non-noble metal) catalysts.

\section{A R T I C L E I N F O}

\section{Article history:}

Received 28 May 2014

Received in revised form

8 September 2014

Accepted 26 October 2014

Available online 4 November 2014

\section{Keywords:}

Bimetallic nanoparticles

Base

Hydrogenolysis

Lignin

Biomass

\section{G R A P H I C A L A B S T R AC T}

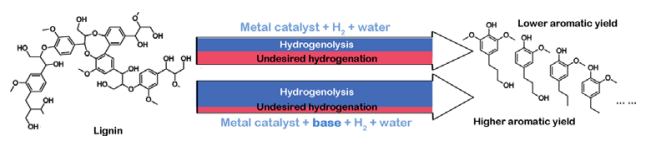

\begin{abstract}
A B S T R A C T
Herein we present a systematic investigation on the promotional effect of base in metal catalysed hydrogenolysis of lignin model compounds and organosolv lignin. The research started with the evaluation of $\mathrm{pH}$ effects ( $\mathrm{pH} 1-14$ ) on the hydrogenolysis of a lignin $\beta-0-4$ model compound over a $\mathrm{Ru}$ catalyst (a stable catalyst over a wide $\mathrm{pH}$ range), from which a significantly increased selectivity towards monomeric compounds was observed in the presence of base. This promotional effect was studied in detail over bimetallic $\mathrm{Ni}_{7} \mathrm{Au}_{3}$ nanoparticles. Addition of a strong base such as $\mathrm{NaOH}$ significantly enhanced the activity and selectivity for C-O bond hydrogenolysis over undesired hydrogenation reactions, not only in lignin model compounds but also in real lignin conversion. Notably, the yield for monomeric aromatic compounds from lignin over $\mathrm{Ni}_{7} \mathrm{Au}_{3}$ catalyst increased ca. $100 \%$ after adding $\mathrm{NaOH}$ as a promoter, under the same reaction conditions. Mechanistic study suggest that addition of base significantly reduced the benzene ring hydrogenation activity of the metal catalysts. The effect of adding different bases over various metal catalysts were also investigated.
\end{abstract}

(c) 2014 Elsevier Ltd. All rights reserved.

\section{Introduction}

Recently, the valorisation of biomass, such as lignin,(Perlack, 2005; Huber et al., 2006; Corma et al., 2007; Stöcker, 2008; Yan

\footnotetext{
*Corresponding author. Tel.: +49 221470 1981; fax: +49 2214701788 .

*** Corresponding author. Tel.: +65 6516 2886; fax: +65 67791936.

E-mail addresses: martin.prechtl@uni-koeln.de (M.H.G. Prechtl), ning.yan@nus.edu.sg (N. Yan).
}

et al., 2010; Long et al., 2012; Long et al., 2013; Mu et al., 2013; Sammons et al., 2013) cellulose(Ngee et al., 2014; Siankevich et al., 2014; Yabushita et al., 2014) and chitin,(Dutta et al., 2004; Chen et al., 2014; Pierson et al., 2014) as sustainable alternative for energy, fuel and chemical production becomes cumulatively interesting. Lignin is the most abundant natural aromatic polymer. New methods that can process lignin into value-added aromatic chemicals are highly desirable.(Sales et al., 2007; Marshall and Alaimo, 2010; Zakzeski et al., 2010; Murat Sen et al., 2012; Azadi 
et al., 2013; Ben et al., 2013; Gao et al., 2014) Lignin consists of interlinked arylpropane units with various functional groups like ethers, methoxy and hydroxyl groups, as well as $\mathrm{C}-\mathrm{C}$ linkages. The most abundant lignin linkage is the $\beta-0-4$ linkage with $45-50 \%$ occurrence in softwood and even more than $60 \%$ in hardwood. Other important ether linkages include the $\alpha-0-4$ and $4-0-5$ linkages with $4-9 \%$ and $6-7 \%$ abundance in hardwood, respectively.(Chakar and Ragauskas, 2004; Zakzeski et al., 2010).

The complex structure of lignin necessitates the employment of model compounds bearing typical linkages in lignin to study the reactivity behaviour (see Fig. 1 for typical C-O linkages in lignin). Although no model compounds can precisely represent the lignin structure, this strategy facilitates the understanding of reaction pathways and mechanisms. The difficulty in breaking the ether bonds in lignin model compounds largely depend on the $\mathrm{C}-\mathrm{O}$ bond energies. $\alpha-0-4$ type of linkages are the weakest with a aliphatic C-O bond dissociation energy between 156 to $203 \mathrm{~kJ} /$ $\mathrm{mol}$, followed by the $\beta-0-4$ linkage (226-303 kJ/mol) and the 4-O5 lignin linkage (346 kJ/mol).(Dorrestijn et al., 2000; Parthasarathi et al., 2011; Younker et al., 2011) The linkages containing C-C bonds possess even higher bond dissociation energies.(Dorrestijn et al., 2000; Parthasarathi et al., 2011; Younker et al., 2011).

Hydrogenolysis of C-O linkages(Kobayashi et al., 2011; Nakagawa and Tomishige, 2012) in lignin, where $\mathrm{H}_{2}$ is used to cleave the $\mathrm{C}-\mathrm{O}$ bond in the presence of a metal catalyst, is regarded as an effective way to transform lignin into depolymerized aromatic platform compounds.(Ruppert et al., 2012; Li et al., 2013; Yan and Dyson, 2013) The complexity of lignin structures makes its depolymerisation a challenging issue and needs the use of appropriate catalysts.(Zakzeski et al., 2010) Early reports date back in 1938 as Harris and Adkins used copper-chromium catalyst for the hydrogenolysis of pretreated aspen hardwood.(Harris et al., 1938) Afterwards Raney Ni,(Baker and Hibbert, 1948; Brewer et al., 1948) Pd, Rh and Ru supported on carbon or $\mathrm{Al}_{2} \mathrm{O}_{3}$, and $\mathrm{Cu}$-doped porous metal oxide(Barta et al., 2010; Matson et al., 2011; Barta et al., 2014) have been tested.(Pepper and Lee, 1969; Pepper and
Fleming, 1978; Pepper and Supathna, 1978) High-temperature approaches were generally applied in these earlier reports to break down the polymer structure catalytically. A clear trend in recent study is the development of catalysts that could be operated under milder conditions in environmentally benign solvents, among which heterogeneous nickel catalysts are of particular interest.(Song et al., 2012; Song et al., 2013; Song et al., 2013) In our group a series of bimetallic NiM ( $M=\mathrm{Au}, \mathrm{Ru}$, $\mathrm{Rh}, \mathrm{Pd}$ ) catalysts were developed that exhibited better performance in lignin hydrogenolysis than single component Ni catalyst, among which NiAu catalyst appears to be most effective.(Zhang et al., 2014).

Undesired benzene ring hydrogenation is a severe problem in lignin hydrogenolysis,(Song et al., 2013) which induces increased hydrogen consumption and decreased efficiency. Moreover, benzene ring hydrogenation leads to stable fully saturated products which do not readily undergo further hydrogenolysis.(He et al., 2012; Zhang et al., 2014) In a few literatures it appears the involvement of a base could improve the selectivity towards monomeric aromatics. For example, $\mathrm{NaO}^{t} \mathrm{Bu}$ is found to be crucial for a Ni carbene complex catalyzed hydrogenolysis of lignin model compounds.(Sergeev and Hartwig, 2011; Sergeev et al., 2012) Wang and Rinaldi reported that a solvent which exhibits high Lewis basicity results in the formation of aromatics over saturated products over Raney Ni in the conversion of lignin model compounds and organosolv lignin.(Wang and Rinaldi, 2012) Other reports followed, concerning hydrogenolysis reactions over heterogeneous catalysts in the presence of base.(Ren et al., 2013; Zaheer et al., 2014) Despite these encouraging results, some questions remain: (I) what is the pH-activity correlation of the reaction, under otherwise identical conditions? (II) what is the optimized pH for the reaction? (III) what is the role of the base? Does the base enhance the rate of $\mathrm{C}-\mathrm{O}$ bond hydrogenolysis, or does it inhibit benzene ring hydrogenation, or both? Therefore we carried out detailed studies on the influence of $\mathrm{pH}$ in lignin hydrogenolysis over Ru and NiAu catalysts. As mentioned above,

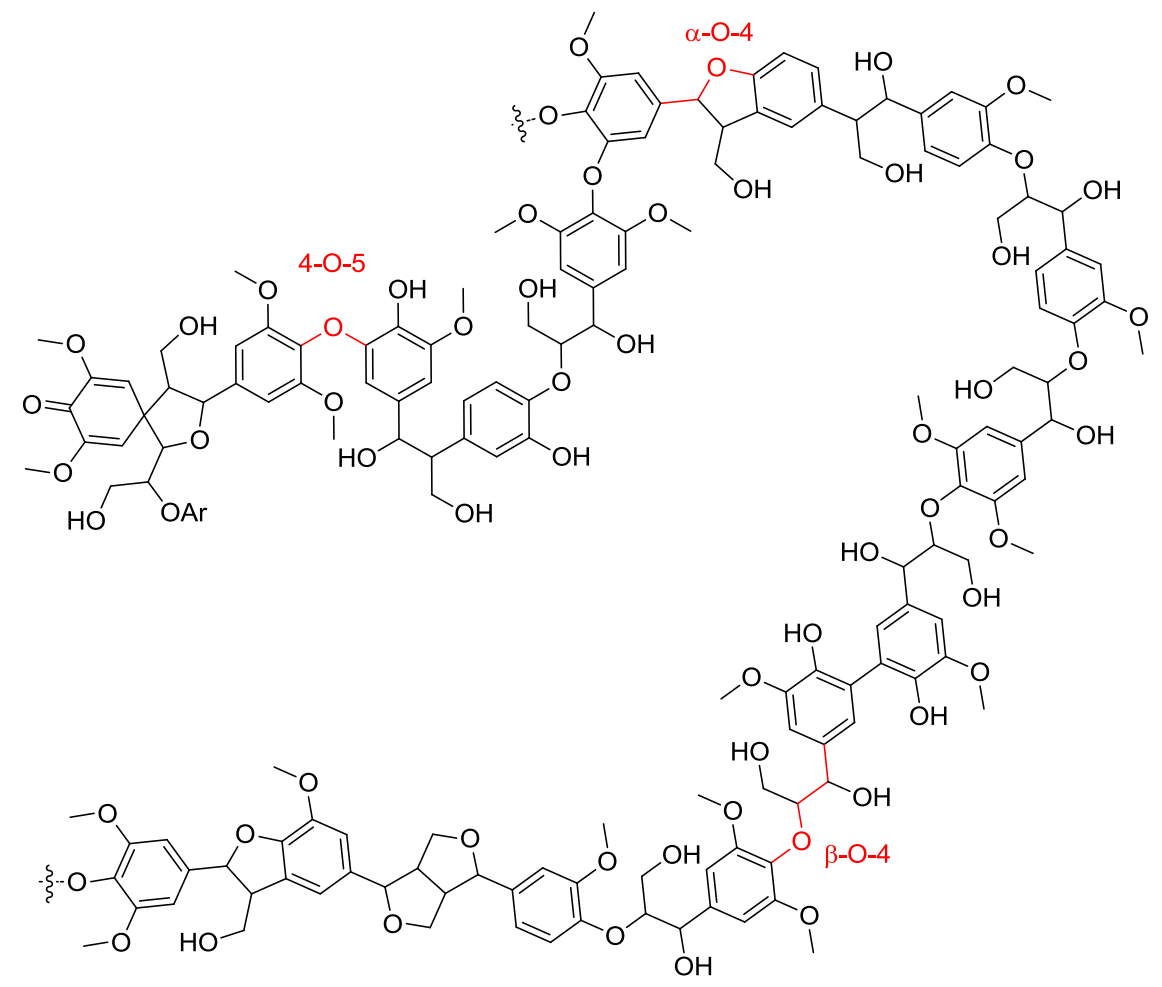

Fig. 1. Schematic fragment structure of hardwood lignin. (Zakzeski et al., 2010). 
$\mathrm{Ni}_{7} \mathrm{Au}_{3}$ was recently identified as a promising catalyst for lignin hydrogenolysis,(Zhang et al., 2014) whereas $\mathrm{Ru}$ is stable under both acidic and basic conditions so that a wide $\mathrm{pH}$ range can be studied. The conversion of lignin model substrates 2-phenoxy-1phenylethanol ( $\beta$-O-4 lignin linkage), 1-(benzyloxy)-2-methoxybenzene ( $\alpha-0-4$ lignin linkage) and diphenyl ether (4-O-5 lignin linkage) have been systematically studied. The unique role of base in lignin hydrogenolysis was identified, which implies that adding base could be used to enhance the selectivity of certain aromatic compounds in lignin hydrogenolysis.

\section{Experimental section}

\subsection{Solvents and reagents}

Solvents and reagents were used as received without further purification if not otherwise mentioned. The chemicals 2methoxyphenol ( $\geq 98 \%)$, 1-hexene (98\%) and polyvinylpyrrolidone $(M . W .=40000)$ were purchased from Alfa Aesar. Sodium borohydride $(>95 \%)$ was purchased from TCI, 2bromoacetophenone (98\%), phenol ( $\geq 99 \%)$, diphenyl ether (99\%), benzyl bromide (98\%), 2,6-dimethoxyphenol (99\%) and lithium bromide ( $\geq 99 \%$ ) were purchased from Sigma Aldrich. Chloroauric acid ( $\geq 50 \% \mathrm{Au}$ ) and ruthenium(III) chloride ( $\geq 37 \%$ ) were purchased from Shaanxi Kaida Chemical Engineering Co., Ltd. and nickel(II) chloride hexahydrate ( $\geq 98 \%$ ) from Sinopharm Chemical Reagent Co., Ltd.. Sodium hydroxide ( $\geq 99 \%$ ), hydrochloric acid (37\%), as well as the solvent ethyl acetate (AR grade) were purchased from Merck. Potassium carbonate ( $\geq 99 \%$ ) and sodium carbonate ( $\geq 99.5 \%$ ) were purchased from Goodrich Chemical Enterprice (GCE). The solvents dichloromethane, diethyl ether, ethanol, toluene and methanol with analytical reagent grade as well as dimethylformamide (HPLC grade) were purchased from Fisher Chemical. Acetone was received from Aik Moh Paints \& Chemical Pte Ltd. and tetrahydrofuran (HPLC grade) was purchased from Tedia. $\mathrm{H}_{2}$ and $\mathrm{N}_{2}$ (purified grade) were purchased from Singapore Oxygen Air Liquide Pte Ltd. (SOXAL).

\subsection{General procedures}

Catalyst preparations were carried out in a Vacuum Glove Box VG-800 Type Handling Manual from Samplatee with nitrogen as inert gas.

\subsection{Catalysis synthesis and hydrogenolysis of lignin model compounds}

The catalyst preparation was carried out mixing $1.4 \mathrm{ml}$ of $0.011 \mathrm{M}$ (0.07 eq., $0.0154 \mathrm{mmol}) \mathrm{NiCl}_{2} \cdot 6 \mathrm{H}_{2} \mathrm{O}$ stock solution with $0.6 \mathrm{ml}$ of a $0.011 \mathrm{M}(0.03$ eq., $0.0066 \mathrm{mmol}) \mathrm{HAuCl}_{4}$ (50\%Au) stock solution. In this solution $48.9 \mathrm{mg}$ ( 2 eq., $0.44 \mathrm{mmol}$ ) of PVP were dissolved. Then $4.2 \mathrm{mg}$ ( 0.5 eq., $0.11 \mathrm{mmol}$ ) $\mathrm{NaBH}_{4}$ were dissolved in $1 \mathrm{ml} \mathrm{H}_{2} \mathrm{O}$ and were added to the precursor solution. For the reactions without the addition of base $0.4 \mathrm{ml} \mathrm{H}_{2} \mathrm{O}$ were added. For the reactions with the addition of base the $\mathrm{pH}$ was adjusted using $10 \mathrm{M}$ sodium hydroxide solution and $\mathrm{H}_{2} \mathrm{O}$ to obtain the same concentration of $\mathrm{c}_{\mathrm{Cat}}=6.5 \cdot 10^{-3} \mathrm{~mol} / \mathrm{L}$ and a volume of $3.4 \mathrm{ml}$ in all experiments. Then $0.22 \mathrm{mmol}$ of substrate were added to the reactor with the fresh prepared catalyst solution. The reactor was sealed, charged with 10 bar $\mathrm{H}_{2}$ and placed into a preheated silicon oil bath $(1000 \mathrm{rpm})$ at the appropriate temperature. After the appropriate reaction time the reactor was cooled down to room temperature using water. For the reactions using base the reaction mixture was adjusted to $\mathrm{pH}$ 6-7 with $0.5 \mathrm{M}$ hydrochloric acid. The reaction mixture was extracted with $6 \mathrm{ml}$ ethyl acetate and $20 \mu \mathrm{l}$
(0.09 mmol) n-dodecane as internal standard were added. The yield was determined using GC-FID.

\subsection{Hydrogenation of toluene and 1-hexene}

For the hydrogenation reactions of toluene and 1-hexene the catalyst preparation and hydrogenation reaction was carried out using the representative procedure, but $2.2 \mathrm{mmol}$ substrate were used. Before extraction no adjustment of the $\mathrm{pH}$ was carried out.

\subsection{Depolymerisation of organosolv lignin}

For the depolymerisation of organosolv lignin the representative procedure with $50 \mathrm{mg}$ organosolv lignin were used. For determination of the monomer yield the reaction mixture was extracted three times with ethyl acetate and the solvent was evaporated under reduced pressure. To the residue $20 \mu \mathrm{l}$ $(0.09 \mathrm{mmol}) n$-dodecane were added as internal standard and it was dissolved in $1.5 \mathrm{ml}$ dimethylformamide. The yield was determined using GC-FID. For measurement of FT-IR and GPC the reaction mixture was extracted with $25 \mathrm{ml}$ dichloromethane and the solvent was evaporated under reduced pressure.

\section{Results and discussion}

\subsection{Hydrogenolysis of lignin model compounds}

2-phenoxy-1-phenylethanol (1) was employed as a lignin $\beta$-O4 model compound. After reacting with $\mathrm{H}_{2}$ over a metal catalysts, up to 15 products including 7 dimers (2-8) and 8 monomers (916), can be detected by GC-FID and GC-MS (Scheme 1). Total monomer yield can act as an indicator of hydrogenolysis activity of the catalytic system, whereas the total yield of dimers can partially represent hydrogenation activity. To investigate the $\mathrm{pH}$ influence on the hydrogenolysis, Ru was chosen as the catalyst.(Yan et al., 2008; Song et al., 2013) As Ru catalyst is resistant to corrosion and oxidation, it provides reliable results over the whole $\mathrm{pH}$ range. The catalyst was prepared by aqueous phase reduction of $\mathrm{RuCl}_{3}$ by $\mathrm{NaBH}_{4}$ in the presence of PVP,(Zhang et al., 2013) after which it was immediately used to catalyze the reaction between $\mathbf{1}$ and $\mathrm{H}_{2}$ in water at $130{ }^{\circ} \mathrm{C}$ for $0.5 \mathrm{~h}$. Experiments were carried out at an initial $\mathrm{pH}$ ranging from 1.1 to 13.7 , adjusted with $\mathrm{HCl}$ to obtain an acidic and $\mathrm{NaOH}$ for a basic reaction medium.

Ru-catalysed reaction leads to quantitative conversion and the formation of three main products in the $\mathrm{pH}$ range of 3.0 to 13.0. 1-cyclohexyl-2-(cyclohexyloxy)ethan-1-ol (4) forms via hydrogenation of both aromatic rings. Monomers 1-cyclohexylethanol (12) and cyclohexanol (16) results from tandem hydrogenolysis/hydrogenation of the substrate. Fig. 2 shows the yield of the three main products $(4,12,16)$ as well as the desired aromatic monomers 1phenylethanol (11) and phenol (15) as a function of the $\mathrm{pH}$ value. Without the addition of acid or base the reaction mixture has an initial $\mathrm{pH}$ of 8.4. This slightly basic reaction medium is due to the decomposition byproducts of $\mathrm{NaBH}_{4}$ used to reduce $\mathrm{RuCl}_{3}$. A decrease of the $\mathrm{pH}$ to 7.1, 4.9 and 3.0 leads to a decrease of the formation of monomers and increased yield of $\mathbf{4}$, indicating inhibition of hydrogenolysis. For instance, 4 was obtained with $93 \%$ yield at $\mathrm{pH}=3.0$ whereas $\mathbf{1 2}$ forms in $1.4 \%$ and $\mathbf{1 6}$ in $2.9 \%$ yield. Thus, an increase of the acidity of the reaction medium leads to a higher selectivity for hydrogenation over hydrogenolysis. A further decrease of $\mathrm{pH}$ to 1.1 results in a significant decrease in activity with only $63 \%$ conversion. In addition the cleavage of the hydroxyl group moieties, probably by acid catalysed dehydration followed by $\mathrm{C}=\mathrm{C}$ bond hydrogenation (the yield for each individual 


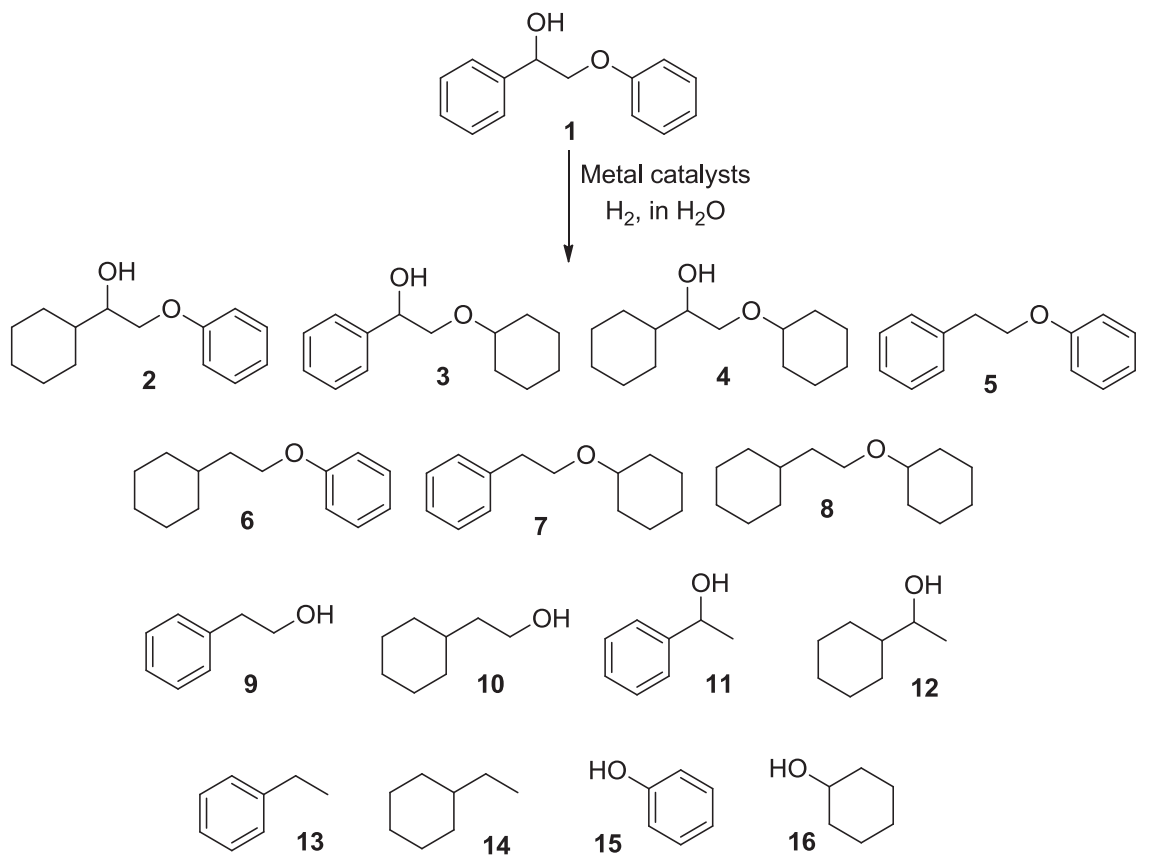

Scheme 1. Reaction scheme of the metal catalysed hydrogenolysis/hydrogenation of $\beta$-O-4 lignin linkage 2-phenoxy-1-phenylethanol (1) with 15 possible selected products.

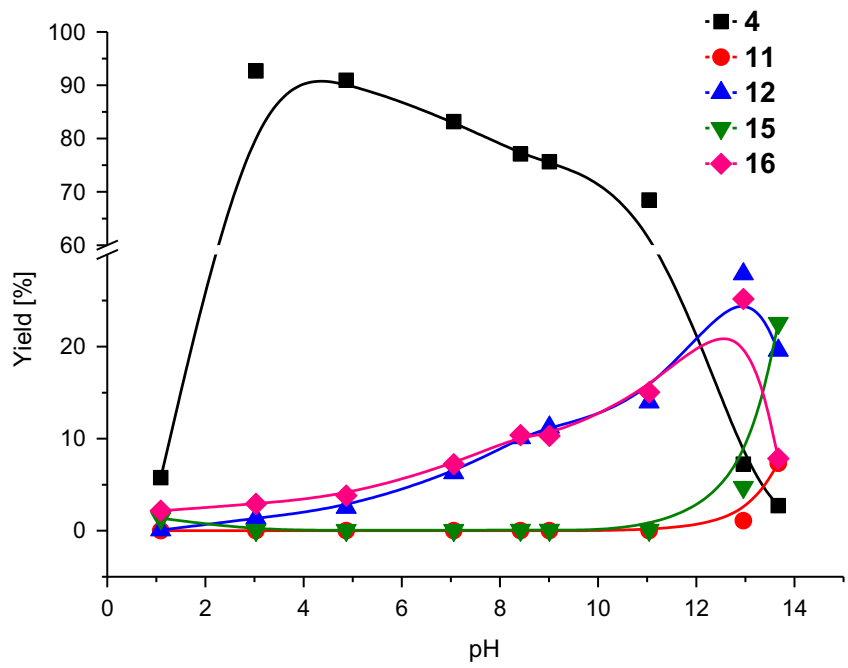

Fig. 2. Yields of main products after hydrogenolysis of 2-phenoxy-1-phenylethanol (1) over Ru as a function of pH. Reaction conditions: $10 \mathrm{~mol} \% \mathrm{Ru}, 10$ bar $\mathrm{H}_{2}, \mathrm{H}_{2} \mathrm{O}$, $130{ }^{\circ} \mathrm{C}, 0.5 \mathrm{~h}$.

product is provided in Table S1). By a sharp contrast, change the $\mathrm{pH}$ to higher values of 9.0,11.0 and 13.0 induced a decrease in the formation of $\mathbf{4}$ and accordingly, enhanced yield of the monomers 12 and 16. In addition, at pH 13.0 slightly increased yields of the aromatic monomers $\mathbf{1 5}$ and $\mathbf{1 1}$ were also observed. An even higher $\mathrm{pH}$ of 13.7 led to a reduced conversion and higher product diversity. Nevertheless, the highest yields of the aromatic monomers was obtained under this condition, that is, $7.3 \%$ of $\mathbf{1 1}$ and $22.6 \%$ of $\mathbf{1 5}$, respectively.

These results indicate low $\mathrm{pH}$ is detrimental to the hydrogenolysis of $\mathbf{1}$ resulting in saturated dimers as the main product. Adding base can increase the selectivity towards hydrogenolysis, especially at a $\mathrm{pH}$ range of $10-14$. We next switch the focus to $\mathrm{Ni}_{7} \mathrm{Au}_{3}$ catalyst, which is much more effective in lignin hydrogenolysis than $\mathrm{Ru}$ under the same reaction conditions. $\mathrm{Ni}_{7} \mathrm{Au}_{3}$ catalyst decomposes under acidic conditions but is stable in the presence of a base.

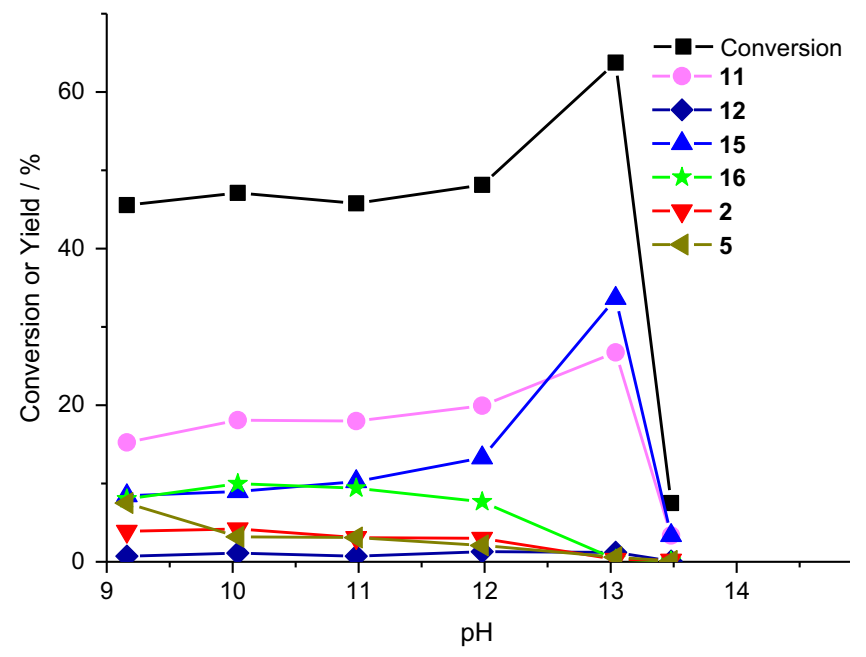

Fig. 3. Yields of main products after hydrogenolysis of 2-phenoxy-1-phenylethanol (1) over $\mathrm{Ni}_{7} \mathrm{Au}_{3}$ as a function of $\mathrm{pH}$. Other products $<1 \%$ yield. Reaction conditions: 10 mol\% $\mathrm{Ni}_{7} \mathrm{Au}_{3}, \mathrm{NaOH}, 10$ bar $\mathrm{H}_{2}, \mathrm{H}_{2} \mathrm{O}, 130{ }^{\circ} \mathrm{C}, 0.5 \mathrm{~h}$.

$\mathrm{Ni}_{7} \mathrm{Au}_{3}$ catalyst is prepared in a similar way as the Ru catalyst, except that $\mathrm{HAuCl}_{4}$ and $\mathrm{NiCl}_{2} \bullet 6 \mathrm{H}_{2} \mathrm{O}$ were applied as the catalyst precursor. This catalyst exhibits a Au@Ni core-shell structure with electron enriched surface Ni.(Zhang et al., 2014) The entire synthetic procedure was conducted in a glovebox to prevent initial oxidation of the catalyst. Hydrogenolysis of $\mathbf{1}$ over $\mathrm{Ni}_{7} \mathrm{Au}_{3}$ catalyst was evaluated at pH 9.2, 10.0, 11.0, 12.0, 13.0 and 13.5, respectively at $130{ }^{\circ} \mathrm{C}$ (see Fig. 3 and detailed results in Table S2).

Again, the reaction turned out to be more effective at basic conditions. The conversion increased from $45.6 \%$ at $\mathrm{pH} 9.2$ to $63.7 \%$

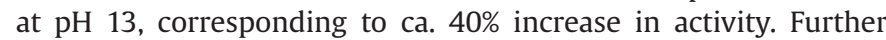
increasing the $\mathrm{pH}$ to 13.5 , however, dramatically decreased the conversion to $7.5 \%$. Aggregation of $\mathrm{Ni}_{7} \mathrm{Au}_{3}$ nanoparticles was observed under this extreme basic condition, which is responsible for the low activity. Increase the $\mathrm{pH}$ from 9.2 to 13.0 also affected the product selectivity. At pH 9.2 a variety of products, including fully and half saturated dimers, aromatic dimers as well as aromatic and saturated monomers, are all present with appreciable yields. 
On the contrary, aromatic monomers become the dominant products as $\mathrm{pH}$ increases. $\mathbf{1 1}$ and $\mathbf{1 5}$ which are formed by hydrogenolysis of the $\mathrm{C}-\mathrm{O}$ bond, reach their maximum at $\mathrm{pH} 13.0$ with yields of $26.7 \%$ and $33.6 \%$, respectively. At the same time the products whose formation involves the aromatic ring hydrogenation, such as like 1-cyclohexylethanol (12) and cyclohexanol (16) are significantly reduced.

Next, the $\mathrm{pH}$ range between 12 and 13 was investigated in more detail (Table 1 and detailed results in Table S3). As the catalyst is freshly prepared for every reaction and the reducing agent $\mathrm{NaBH}_{4}$ influences the $\mathrm{pH}$, this value can differ slightly for every single experiment. For the following experiments, the $\mathrm{NaOH}$ amount is given in equivalents with regard to the substrate $\mathbf{1}$ which covers the $\mathrm{pH}$ range between 12.0 and 13.0. Moreover, in these optimisation studies the temperature was reduced to $100{ }^{\circ} \mathrm{C}$ to prevent any catalyst deactivation. From pH 12 to 13 a slightly increase in the conversion of the $\beta$-O- 4 lignin linkage is observable, reaching its maximum at 1.8 and 2.7 eq. of $\mathrm{NaOH}$. Between the two, 2.7 eq. of $\mathrm{NaOH}$ seems to be more effective in inhibiting the formation of saturated products (as indicated by a larger 15:16 ratio) and therefore was chosen for further investigations.

Kinetic experiments over a period of $2 \mathrm{~h}$, both in the presence and absence of 2.7 eq. of $\mathrm{NaOH}$, were carried out to understand the reaction as a function of time (Fig. 4). The $\mathrm{Ni}_{7} \mathrm{Au}_{3}$ catalyst is stable under the condition, irrespective of base addition, as suggested by continuously increased substrate conversion over a period of $2 \mathrm{~h}$ at $100{ }^{\circ} \mathrm{C}$. Almost quantitative yield was achieved when base was added, in comparison with $61.1 \%$ conversion without $\mathrm{NaOH}$, further testifying that $\mathrm{Ni}_{7} \mathrm{Au}_{3}$ catalyst is intrinsically more active

Table 1

Conversion of the hydrogenolysis of 2-phenoxy-1-phenylethanol (1) over $\mathrm{Ni}_{7} \mathrm{Au}_{3}$ with different $\mathrm{NaOH}$ amounts ( $\mathrm{pH} 9.2,12.0-13.0$ ). Ratio of aromatic monomers 15 to corresponding hydrogenated monomer 16 as a function of the $\mathrm{NaOH}$ amount.

\begin{tabular}{lllccc}
\hline Entry & $\begin{array}{l}\mathrm{NaOH} \\
\text { [eq.] }\end{array}$ & $\begin{array}{l}\text { Conversion } \\
{[\%]}\end{array}$ & $\begin{array}{l}\text { Phenol } \\
\mathbf{1 5}[\%]\end{array}$ & $\begin{array}{l}\text { Cyclohexanol } \\
\mathbf{1 6}[\%]\end{array}$ & $\begin{array}{l}\text { Ratio } \\
\mathbf{1 5} / \mathbf{1 6}\end{array}$ \\
\hline 1 & 0 & 21.9 & 2.5 & 3.8 & 0.7 \\
2 & 0.5 & 23.2 & 8.0 & 1.9 & 4.3 \\
3 & 1 & 26.9 & 9.7 & 0.7 & 14.1 \\
4 & 1.8 & 33.9 & 15.9 & 0.7 & 24.5 \\
5 & 2.7 & 33.6 & 15.0 & 0.4 & 34.1 \\
6 & 4.6 & 17.1 & 8.2 & $<0.1$ & 104.8 \\
\hline
\end{tabular}

Reaction conditions: 10 mol\% $\mathrm{Ni}_{7} \mathrm{Au}_{3}, 10$ bar $\mathrm{H}_{2}, \mathrm{H}_{2} \mathrm{O}, 100{ }^{\circ} \mathrm{C}, 0.5 \mathrm{~h}$.

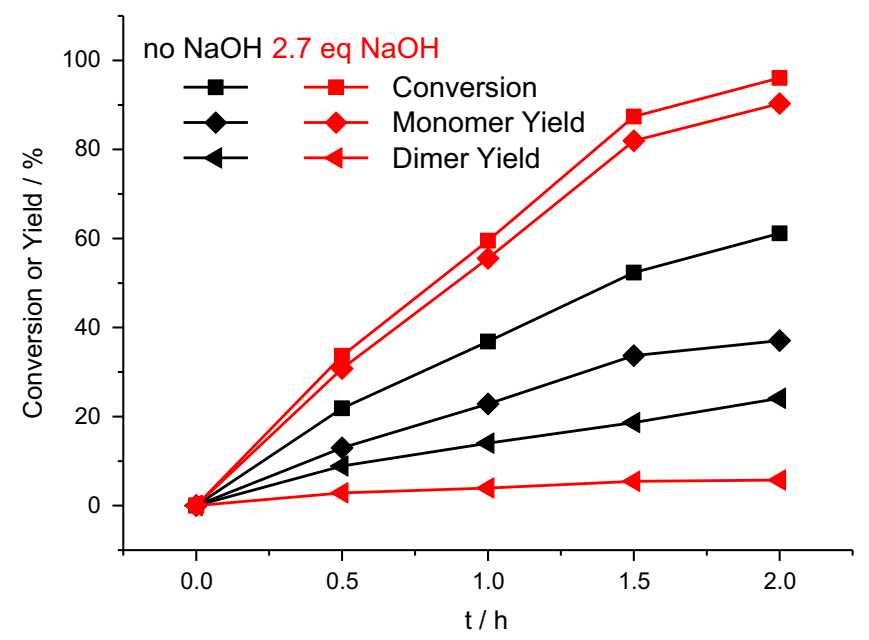

Fig. 4. Kinetic studies of the hydrogenolysis of 2-phenoxy-1-phenylethanol (1) over $\mathrm{Ni}_{7} \mathrm{Au}_{3}$ without base and the addition of 2.7 eq. $\mathrm{NaOH}$. Reaction conditions: $10 \mathrm{~mol} \% \mathrm{Ni}_{7} \mathrm{Au}_{3}, 10$ bar $\mathrm{H}_{2}, \mathrm{H}_{2} \mathrm{O}, 100{ }^{\circ} \mathrm{C}$. Conversion, yield of monomers (9-16) and dimers (2-8). and selective when $\mathrm{NaOH}$ is added. Furthermore, using base significantly improves the selectivity. The total monomer yield after $2 \mathrm{~h}$ is about $90.3 \%$ whereas the total monomer yield without the addition of base is just $37.1 \%$. A closer inspection on the yield of aromatic $(9,11,13,15)$ and saturated $(10,12,14,16)$ monomers (Table S4 and S5) reveals that using base as additive hinders the formation of saturated monomers. The experiment with base results in the formation of $90.3 \%$ total monomers yield with $76.9 \%$ aromatic units and only $13.4 \%$ hydrogenated monomers after $2 \mathrm{~h}$. Without base, the total monomer yield (37.1\%) consists of $17.9 \%$ aromatic and $19.1 \%$ saturated monomers. The kinetic experiments also suggest that the rate of cleavage of fully saturated dimers is low due to the absence of an observable decrease of these compounds as the reaction progresses (Table S4 and S5).

Lignin contains a plenty of methoxy and hydroxyl groups. Thus, model compounds containing a $\mathrm{C}_{\gamma}-\mathrm{OH}$ or hydroxyl and methoxy groups at the aryl moiety, are very convenient to mimic its reactivity.(Zakzeski et al., 2010) As such, the influence of $\mathrm{NaOH}$ on the hydrogenolysis of methoxy-substituted $\beta$-0-4 lignin linkage model compounds, 2-(2-methoxyphenoxy)-1-phenylethanol (1a) and 2-(2,6-dimethoxyphenoxy)-1-phenylethanol (1b), were tested (Scheme S1). To our delight, the addition of base also results in a higher rate of the hydrogenolysis reaction and enhanced selectivity for these two substrates (Table S8 and S9).

The reactivity behaviour of other typical lignin linkages was also investigated. In lignin, the $\alpha-0-4$ linkage represents the weakest ether bonds to cleave due to the lower bond dissociation energy compared to the $\beta-0-4$ linkage. ${ }^{[7,11]}$ In Table 2 , the addition of 0 to 2.7 eq. $\mathrm{NaOH}$ ( $\mathrm{pH} 9.2-12.8$ ) did not change the activity significantly, and base addition exhibited negelible influence on the selectivity of aromatic monomers (18 and 15a). Nonetheless, the partical hydrogenated product yield (16a, and $\mathbf{2 1}$ ) decreased with increasing base addition, indicating hindrence effect of base to hydrogenation of benzene ring. This suggest the base promotional effect in lignin hydrogenolysis to be an indirect effect, i.e., through the inhibition of benzene ring hydrogenation instead of directly activiting the $\mathrm{C}-\mathrm{O}$ bond. As such, for the $\alpha-\mathrm{O}-4$ linkage which is intrincically weak, no base promotional effect in $\mathrm{C}-\mathrm{O}$ bond hydrogenolysis could be observed.

The third most abundant ether bond in lignin is the 4-O-5 linkage, featured by the direct connection of one aromatic ring on each side of oxygen (see Table 3 for the structure). Compared to the ether bonds in $\beta-0-4$ and $\alpha-0-4$ linkages, this is the most challenging bond to cleave, because of a higher bond dissociation energy.(Zakzeski et al., 2010; Parthasarathi et al., 2011) At $100{ }^{\circ} \mathrm{C}$ after 5 h reaction time the conversion of $\mathbf{2 2}$ decreased from $33.7 \%$ to $22.8 \%$ by adding 2.7 eq. $\mathrm{NaOH}$ (Table 3 , entries 1 and 2 ). Nevertheless, the selectivity improved dramatically. In the reaction without base only trace amount of phenol was detected (Table 3, entry 1 ), but becomes one of the major products when $2.7 \mathrm{eq}$. $\mathrm{NaOH}$ was added.

\subsection{Depolymerisation of organosolv lignin}

The valorisation of lignin into smaller molecular weight compounds is often more challenging and requires harsh reaction conditions.(Zakzeski et al., 2010) We next evaluated the combination of $\mathrm{NaOH}$ and $\mathrm{Ni}_{7} \mathrm{Au}_{3}$ catalyst for real lignin hydrogenolysis into aromatic compounds. The organosolv lignin from birch sawdust was used. At $100{ }^{\circ} \mathrm{C}$ no monomers could be detected, thus higher temperatures from $120-160{ }^{\circ} \mathrm{C}$ were tested (Table S10). By GC-MS analysis products 25-28 were identified as the major monomeric products (Table 4, Fig. S1-S4). The total monomer yield results from the sum of the identified monomers 25-28 (the actual total monomer yield should be higher as there are unidentified monomers, despite in small amount). 
Table 2

Conversion and main product yields of the hydrogenolysis of 1-(benzyloxy)-2-methoxybenzene (17) over $\mathrm{Ni}_{7} \mathrm{Au}_{3}$ as a function of the $\mathrm{NaOH}$ amount.

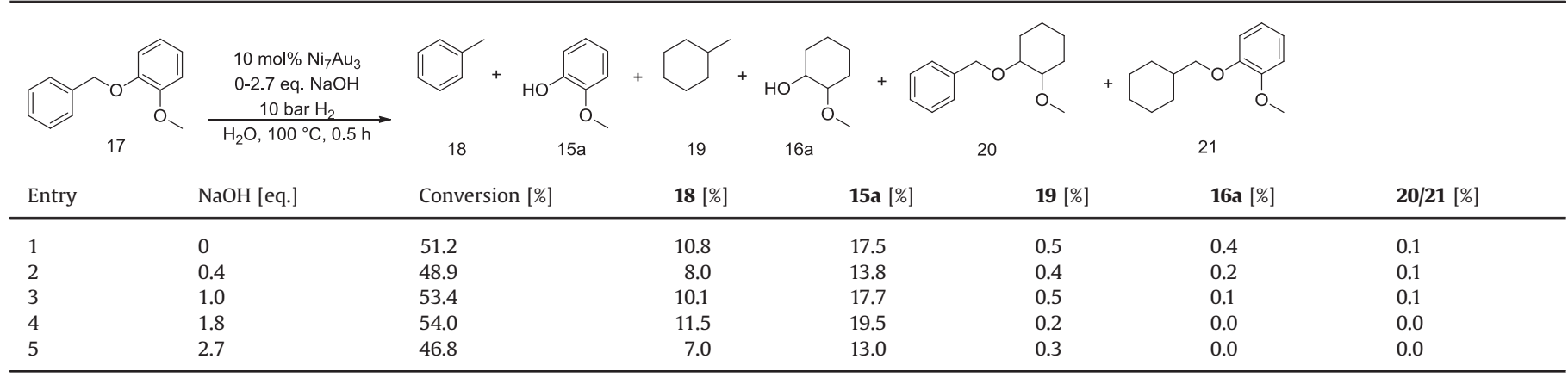

Reaction conditions: $10 \mathrm{~mol}^{2} \mathrm{Ni}_{7} \mathrm{Au}_{3}, 0-2.7$ eq. $\mathrm{NaOH}, 10$ bar $\mathrm{H}_{2}, \mathrm{H}_{2} \mathrm{O}, 100{ }^{\circ} \mathrm{C}, 0.5 \mathrm{~h}$.

Table 3

Conversion and main products yield of the hydrogenolysis of diphenyl ether (23) over $\mathrm{Ni}_{7} \mathrm{Au}_{3}$ as a function of the pH amount.

\begin{tabular}{|c|c|c|c|c|c|c|c|}
\hline \multirow[b]{2}{*}{ Entry } & \multicolumn{2}{|c|}{$\begin{array}{c}10 \text { mol\% } \mathrm{Ni}_{7} \mathrm{Au}_{3} \\
0 / 2.7 \text { eq. } \mathrm{NaOH} \\
10 \text { bar } \mathrm{H}_{2} \\
\mathrm{H}_{2} \mathrm{O}, 100^{\circ} \mathrm{C}\end{array}$} & \multirow{2}{*}{15} & \multirow[b]{2}{*}{15 [\%] } & \multirow[b]{2}{*}{$16[\%]$} & \multirow[b]{2}{*}{23 [\%] } & \multirow[b]{2}{*}{$24[\%]$} \\
\hline & $\mathrm{NaOH}$ [eq.] & $\mathrm{t}[\mathrm{h}]$ & & & & & \\
\hline 1 & 0 & 5 & 33.7 & 0.2 & 17.3 & 2.2 & 0.5 \\
\hline 2 & 2.7 & 5 & 22.8 & 4.1 & 5.4 & 0.8 & 0.1 \\
\hline 3 & 2.7 & 15 & 37.2 & 6.5 & 12.3 & 1.4 & 0.2 \\
\hline
\end{tabular}

Reaction conditions: 10 mol\% $\mathrm{Ni}_{7} \mathrm{Au}_{3}, \mathrm{NaOH}, 10$ bar $\mathrm{H}_{2}, \mathrm{H}_{2} \mathrm{O}, 100{ }^{\circ} \mathrm{C}$.

Table 4

Conversion and main products yield of the hydrogenolysis of organosolv lignin over $\mathrm{Ni}_{7} \mathrm{Au}_{3}$.

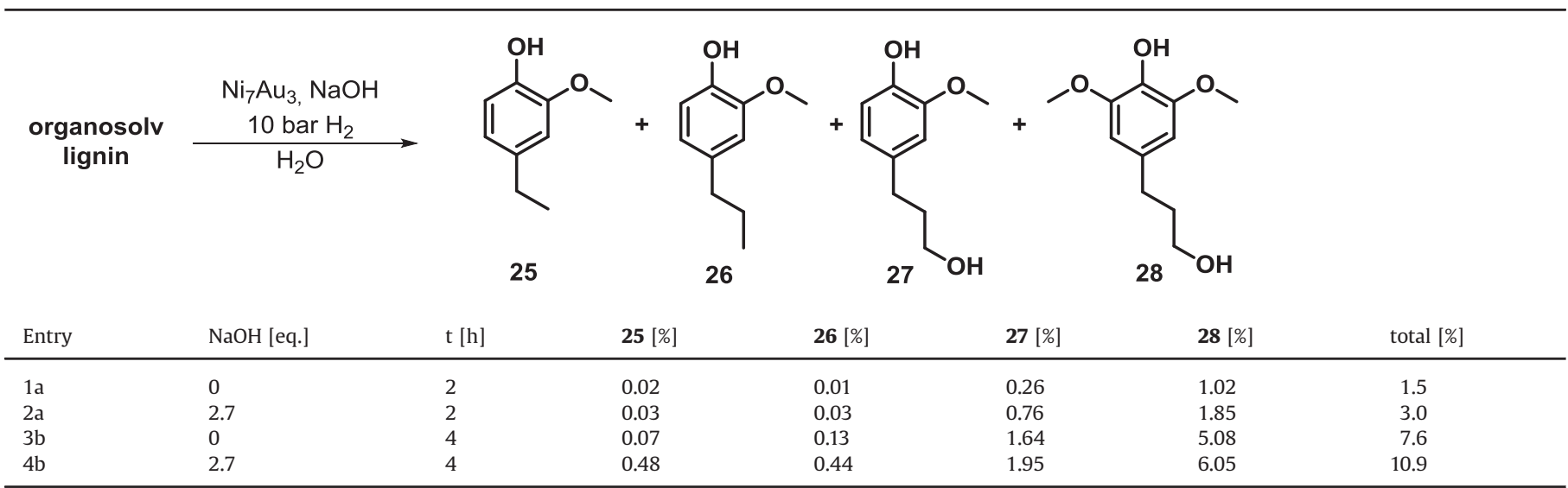

Reaction conditions: $0.022 \mathrm{mmol} \mathrm{Ni}_{7} \mathrm{Au}_{3}, 50 \mathrm{mg}$ organosolv lignin, 10 bar $\mathrm{H}_{2}, \mathrm{H}_{2} \mathrm{O},{ }^{\mathrm{a}} 130{ }^{\circ} \mathrm{C}$ and ${ }^{\mathrm{b}} 160{ }^{\circ} \mathrm{C}$.

Table 4 shows the total monomer yield as a function of the $\mathrm{NaOH}$ amount at $130{ }^{\circ} \mathrm{C}$ and $160{ }^{\circ} \mathrm{C}$. Encouragingly, the base additive promotes the total monomer yield at both temperatures after adding $\mathrm{NaOH}$, which is in perfect agreement with the experiments with lignin model substrates. As the promotional effect does not change significantly with temperatures, $130{ }^{\circ} \mathrm{C}$ was chosen for further investigations as the catalyst is more stable under this condition. Table S11 shows the time dependent total monomer yield of the depolymerisation reaction of organosolv lignin using the selected reaction conditions of $0.6 \mathrm{mmol}$ $\mathrm{NaOH}$ at $130^{\circ} \mathrm{C}$. The kinetic studies show after $14.5 \mathrm{~h}$ a total monomer yield of $5.4 \mathrm{wt} \%$. Without base $3.3 \mathrm{wt} \%$ monomers were obtained under the same condition (Table S11).

The FT-IR spectra(Suni et al., 2010; Azadi et al., 2012; Mao et al., 2012; Sammons et al., 2013) of organosolv lignin, and the recovered residues after the reaction are compiled in Fig. 5. In organosolv lignin the band at $2939 \mathrm{~cm}^{-1}$ and $2843 \mathrm{~cm}^{-1}$ can be assigned to the $\mathrm{C}-\mathrm{H}$ stretching vibrations in methyl and methylen groups. The reaction with the addition of $\mathrm{NaOH}$ shows nearly the same bands, except a slight shift from $2939 \mathrm{~cm}^{-1}$ to $2933 \mathrm{~cm}^{-1}$. In the case of the reaction without base one additional vibration at $2961 \mathrm{~cm}^{-1}$ appears. Moreover, the bands at $2939 \mathrm{~cm}^{-1}$ and $2843 \mathrm{~cm}^{-1}$ are shifted to $2924 \mathrm{~cm}^{-1}$ and $2853 \mathrm{~cm}^{-1}$, respectively. The fact that the stretching vibration bands for $\mathrm{CH}_{3}$ and $\mathrm{CH}_{2}$ are shifted and increase in intensities supports the assumption of a higher hydrogenation activity resulting in saturated rings preventing the depolymerisation in the absence of $\mathrm{NaOH}$. In addition, the stretching vibration of $\mathrm{C}-\mathrm{O}$ bond in guaiacyl units shifted from $1271 \mathrm{~cm}^{-1}$ to $1260 \mathrm{~cm}^{-1}$ and the in plane deformation vibrations 


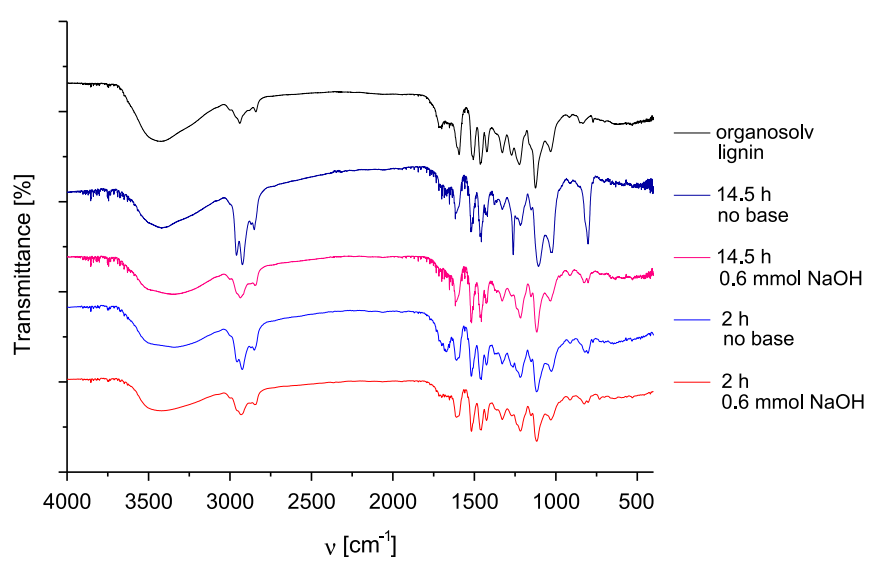

Fig. 5. FT-IR spectra of organosolv lignin and depolymerisation reactions of lignin catalysed by $\mathrm{Ni}_{7} \mathrm{Au}_{3}$. Reaction conditions: $50 \mathrm{mg}$ organosolv lignin, $0.022 \mathrm{mmol}$ $\mathrm{Ni}_{7} \mathrm{Au}_{3}, 10$ bar $\mathrm{H}_{2}, \mathrm{H}_{2} \mathrm{O}, 130{ }^{\circ} \mathrm{C}$.

of $\mathrm{C}-\mathrm{H}$ bonds in guaiacyl units and stretching vibration of $\mathrm{C}-\mathrm{O}$ bonds in primary alcohols shifted from $1029 \mathrm{~cm}^{-1}$ to $1022 \mathrm{~cm}^{-1}$, respectively, in the absence of base. All those results indicate that adding $\mathrm{NaOH}$ better preserve the lignin structure, enabling a more selective depolymerisation.

\subsection{Mechanistic studies}

Reaction in the absence of $\mathrm{Ni}_{7} \mathrm{Au}_{3}$, but with identical amount of PVP, $\mathrm{NaBH}_{4}$ and 2.7 eq. $\mathrm{NaOH}$, at $130{ }^{\circ} \mathrm{C}$ showed only $0.1 \%$ conversion of the $\mathbf{1}$ after $0.5 \mathrm{~h}$. Under the same condition, organosolv lignin provided merely $0.1 \mathrm{wt} \%$ of 4-(3-hydroxypropyl)-2-methoxyphenol (27) after $4 \mathrm{~h}$ reaction (see SI for detailed control experiments procedure). These results suggest the reaction follows a metal-catalysed reaction pathway, instead of a basecatalysed hydrolysis. $\mathrm{Ni}_{7} \mathrm{Au}_{3}$ catalyst was characterised using TEM, UV-vis and XPS measurements (Fig. S7-11), revealing there is no appreciable differences in these spectra at $\mathrm{pH} 9$ and 13. Thus, the catalyst itself does not experience structural or chemical changes after the addition of $\mathrm{NaOH}$.

At higher pHs, phenols are existing as phenolates in water solution, which has a much higher solubility. The calculated energy gap of the hydration energy for phenol and phenolate is $6.38 \mathrm{eV}$,(Ghosh et al., 2012) indicating that phenolate is much better solvated than phenol in water. Consequently, the reaction barrier for phenolate to be absorbed and hydrogenated over the catalyst surface would be higher. This is likely to be part of the reason that the selectivity towards aromatic compounds is higher under basic conditions. Nevertheless, we observed that the hydrogenation of all aromatic compounds were inhibited at higher pHs, indicating solvation is not the only reason for the inhibition effect. Thus, hydrogenation reactions of toluene and 1-hexene over $\mathrm{Ni}_{7} \mathrm{Au}_{3}$ were carried out to obtain insight into the hydrogenation behaviour of $\mathrm{C}=\mathrm{C}$ bonds with base additive (Fig. 6). Toluene was used as simple aromatic substrate whereas 1-hexene has a nonhindered terminal $\mathrm{C}=\mathrm{C}$ bond.

For the hydrogenation of toluene to methylcyclohexane, the reaction rate was significantly reduced in the presence of base. In addition, the apparent activation energy was calculated using the Arrhenius plot which showed no significant change as in both cases the value for the apparent activation energy results in about $E_{A}=46.1-47.9 \mathrm{~kJ} / \mathrm{mol}$ (Fig. S12). These values correlate with literature data for hydrogenations of toluene over heterogeneous catalysts. (Keane and Patterson, 1996; Prechtl et al., 2008) On the other hand, the pre-exponential factor $A$, which provides information on the collision rate of the molecules and particles, changed considerably. (Atkins and de Paula, 2006) For the reaction without base, the value
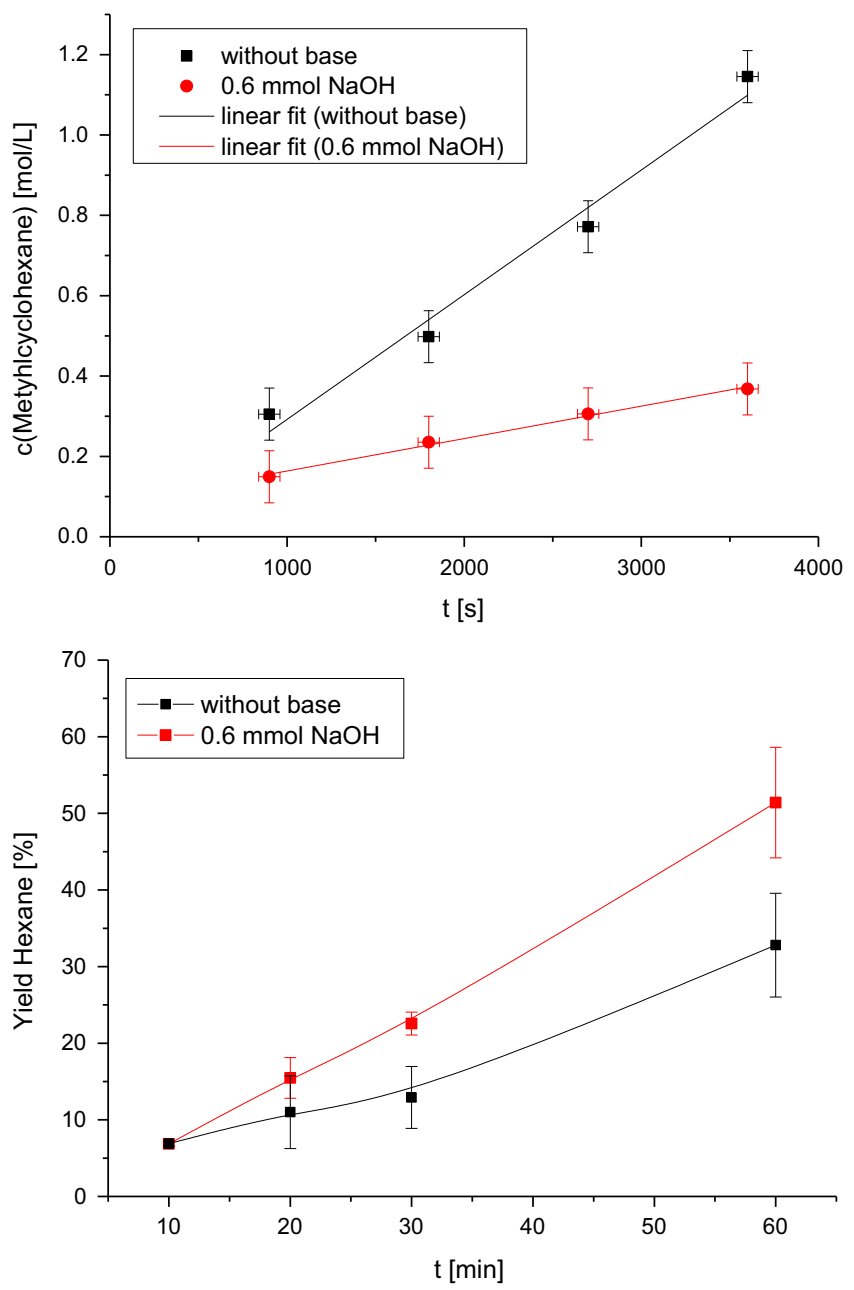

Fig. 6. (a) Hydrogenation of toluene over $\mathrm{Ni}_{7} \mathrm{Au}_{3}$ without base and the addition of $0.6 \mathrm{mmol} \mathrm{NaOH}$. Linear fit with margin of error: $\Delta \mathrm{t}= \pm 60 \mathrm{~s}, \Delta \mathrm{c}= \pm 0.06 \mathrm{~mol} / \mathrm{L}$. Reaction conditions: $2.2 \mathrm{mmol}$ toluene, $0.022 \mathrm{mmol} \mathrm{Ni}_{7} \mathrm{Au}_{3}, 10$ bar $\mathrm{H}_{2}, \mathrm{H}_{2} \mathrm{O}, 130{ }^{\circ} \mathrm{C}$. (b) Hydrogenation of 1 -hexene over $\mathrm{Ni}_{7} \mathrm{Au}_{3}$ without base and the addition of $0.6 \mathrm{mmol} \mathrm{NaOH}$. Reaction conditions: $2.2 \mathrm{mmol}$ 1-hexene, $0.022 \mathrm{mmol} \mathrm{Ni}_{7} \mathrm{Au}_{3}$, $\mathrm{H}_{2} \mathrm{O}, 30{ }^{\circ} \mathrm{C}$. Lines are just shown for visualisation.

of $A$ is 812 , which is ca. five times higher than that in the presence of base $(A=151)$. In view of the reaction mechanism this indicates a hindered coordination of the aromatic ring on the catalyst surface.

In agreement with this, no hindered hydrogenation of 1hexene was observed in the presence of base. In fact, the addition of base seems to accelerate the hydrogenation reaction of the terminal alkene. Combining these two studies, the inhibiting effect of the base on the aromatic ring hydrogenation is due the increased hindrance caused by competitive adsorption of base on catalyst surface.

The promotional effect in hydrogenolysis of $\mathbf{1}$ were tested over various bases (Table 5 and detailed results in Table S6). KOH and LiOH exhibited similar results of the enhancement in activity and selectivity. These strong bases resulted in a high $\mathrm{pH}$ value of $12.3-$ 12.9 and similar concentration of hydroxyl ions in the reaction media. The addition of the much weaker bases such as $\mathrm{K}_{2} \mathrm{CO}_{3}$ or $\mathrm{Na}_{2} \mathrm{CO}_{3}$ resulted in a decrease of activity. The organic base $\mathrm{Et}_{3} \mathrm{~N}$ exhibited negligible effect in activity, but the selectivity for the formation of aromatics such as phenol increased. Overall it appears that $\mathrm{OH}^{-}$is crucial for the enhanced activity and selectivity, further suggesting the proposed competitive absorption between aromatic rings and hydroxyl ions.

Investigations on different metal catalysts revealed that the base promotional effect in lignin hydrogenolysis appears to be 
Table 5

Hydrogenolysis of of 2-phenoxy-1-phenylethanol (1) over $\mathrm{Ni}_{7} \mathrm{Au}_{3}$ with different bases.

\begin{tabular}{llrlrc}
\hline Entry & Base & $\mathrm{pH}$ & Conversion [\%] & \multicolumn{2}{c}{ Yield [\%] } \\
\hline & & & & $\mathbf{1 1}$ & $\mathbf{1 5}$ \\
1 & - & 9.2 & 36.9 & 9.9 & 3.1 \\
2 & $\mathrm{NaOH}$ & 12.8 & 59.5 & 24.4 & 26.6 \\
3 & $\mathrm{KOH}$ & 12.9 & 56.1 & 20.9 & 30.0 \\
4 & $\mathrm{LiOH}$ & 12.3 & 68.5 & 25.6 & 33.6 \\
5 & $\mathrm{~K}_{2} \mathrm{CO}_{3}$ & 11.0 & 28.3 & 10.9 & 12.2 \\
6 & $\mathrm{Na}_{2} \mathrm{CO}_{3}$ & 10.9 & 27.4 & 10.3 & 10.7 \\
7 & $\mathrm{Et}_{3} \mathrm{~N}$ & 11.0 & 34.5 & 12.7 & 8.0 \\
\hline
\end{tabular}

Reaction conditions: 10 mol\% $\mathrm{Ni}_{7} \mathrm{Au}_{3}, 2.7$ eq. base, 10 bar $\mathrm{H}_{2}, \mathrm{H}_{2} \mathrm{O}, 100{ }^{\circ} \mathrm{C}, 1 \mathrm{~h}$.

Table 6

Hydrogenolysis of 2-phenoxy-1-phenylethanol (1) over various metal catalysts.

\begin{tabular}{lllllr}
\hline Entry & {$[\mathrm{M}]$} & $\mathrm{NaOH}$ [eq.] & Conversion [\%] & \multicolumn{2}{c}{ Yield [\%] } \\
& & & & $\mathbf{1 1}$ & $\mathbf{1 5}$ \\
1 & $\mathrm{Ni}_{7} \mathrm{Au}_{3}$ & - & 61.1 & 14.0 & 2.5 \\
2 & & 2.7 & 96.0 & 35.5 & 40.9 \\
3 & $\mathrm{Ni}$ & - & 36.5 & 6.1 & 4.0 \\
4 & & 2.7 & 59.1 & 21.3 & 30.4 \\
5 & $\mathrm{Ni}_{85} \mathrm{Ru}_{15}$ & - & 96.3 & 10.9 & 0.5 \\
6 & & 2.7 & 99.9 & 17.0 & 31.7 \\
\hline
\end{tabular}

Reaction conditions: $10 \mathrm{~mol} \%$ [M], $\mathrm{NaOH}, 10$ bar $\mathrm{H}_{2}, \mathrm{H}_{2} \mathrm{O}, 100{ }^{\circ} \mathrm{C}, 2 \mathrm{~h}$.

applicable to a few other metals (Table 6 and detailed results in Table S7). Over pure Ni catalyst, the addition of 2.7 eq. $\mathrm{NaOH}$ increased the conversion from $36.5 \%$ to $59.1 \%$, and the yield of the two aim products, $\mathbf{1 1}$ and $\mathbf{1 5}$, were significantly increased from $10.1 \%$ to $51.7 \%$ (entry $3-4$ ). Another bimetallic catalyst, $\mathrm{Ni}_{85} \mathrm{Ru}_{15}$, (Zhang et al., 2014) was also evaluated. Despite a high conversion (96.3\%), the yield towards aim products was very low (11.4\%) in the absence of a base. After the addition of 2.7 eq. $\mathrm{NaOH}$, full conversion was achieved, and the yields of $\mathbf{1 1}$ and $\mathbf{1 5}$ reached $17.0 \%$ and $31.7 \%$, respectively.

\section{Conclusions}

We presented a systematic investigation on the influence of $\mathrm{pH}$ in the hydrogenolysis of lignin. Low $\mathrm{pH}$ is detrimental to both activity and aromatic product selectivity, whereas high $\mathrm{pH}$, in particular in the range of $\mathrm{pH} \mathrm{12-13,} \mathrm{exhibits} \mathrm{significant} \mathrm{promo-}$ tional effect. For all tested model substrates a basic reaction medium leads to an increase in selectivity towards aromatic compounds and inhibition for arene hydrogenation. For the $\beta$-O4 linkage model compounds, additionally a promoting effect for $\mathrm{C}_{\mathrm{Alkyl}} \mathrm{O} \mathrm{O}$ bond hydrogenolysis was observed, resulting in a higher activity. More importantly the depolymerisation of organosolv lignin into aromatic monomers is also enhanced considerably using $\mathrm{NaOH}$ as an additive.

The catalyst characterisation using TEM, UV-vis and XPS, as well as the apparent $\mathrm{E}_{\mathrm{A}}$ of the hydrogenation of toluene suggest that there is no change in the nature of the catalyst after adding base. On the other hand, the hydrogenation behaviour towards toluene and 1-hexene indicates that a high amount of the hydroxyl groups in the reactions mixture could adsorb weakly on the catalyst surface and thus hinder the coordination of the bulky aromatic ring. This results in a decreased hydrogenation of arenes and a higher selectivity towards aromatic compounds in the hydrogenolysis of the lignin model compounds and lignin. The synergistic effect of metal catalyst and a base is at least applicable to Ru (a typical noble metal) and $\mathrm{Ni}$ (a typical non-noble metal) catalysts, thus providing a potential strategy to enhance aromatic product yield in lignin hydrogenolysis.

\section{Acknowledgements}

We acknowledge the $A^{*}$ Star, Singapore for the financial support (WBS: R-279-000-403-305). H. K. is grateful for a scholarship granted by Contact Singapore and NUS. M. H. G. P. acknowledges the MIWF-NRW for the Scientist Returnee Award 2009 (NRWRückkehrerprogramm)

\section{Appendix A. Supporting information}

Supplementary data associated with this article can be found in the online version at http://dx.doi.org/10.1016/j.ces.2014.10.045.

\section{References}

Atkins, P.W., de Paula, J., 2006. Wiley-VCG, Physikalische Chemie, Weinheim.

Azadi, P., Carrasquillo-Flores, R., Pagan-Torres, Y.J., Gurbuz, E.I., Farnood, R. Dumesic, J.A., 2012. Catalytic conversion of biomass using solvents derived from lignin. Green Chem. 14 (6), 1573-1576.

Azadi, P., Inderwildi, O.R., Farnood, R., King, D.A., 2013. Liquid fuels, hydrogen and chemicals from lignin: a critical review. Renew. Sust. Energ. Rev. 21 (0), 506-523.

Baker, S.B., Hibbert, H., 1948. Studies on lignin and related compounds. LXXXVI. hydrogenation of dimers related to lignin1. J. Am. Chem. Soc. 70 (1), 63-67.

Barta, K., Matson, T.D., Fettig, M.L., Scott, S.L., Iretskii, A.V., Ford, P.C., 2010. Catalytic disassembly of an organosolv lignin via hydrogen transfer from supercritical methanol. Green Chem. 12 (9), 1640-1647.

Barta, K., Warner, G.R., Beach, E.S., Anastas, P.T., 2014. Depolymerization of organosolv lignin to aromatic compounds over Cu-doped porous metal oxides. Green Chem. 15 (1), 191-196.

Ben, H., Mu, W., Deng, Y., Ragauskas, A.J., 2013. Production of renewable gasoline from aqueous phase hydrogenation of lignin pyrolysis oil. Fuel 103 (0) 1148-1153.

Brewer, C.P., Cooke, L.M., Hibbert, H., 1948. Studies on lignin and related compounds. LXXXIV. the high pressure hydrogenation of maple wood: hydrol lignin1. J. Am. Chem. Soc. 70 (1), 57-59.

Chakar, F.S., Ragauskas, A.J., 2004. Review of current and future softwood kraft lignin process chemistry. Ind. Crop. Prod. 20 (2), 131-141.

Chen, X., Chew, S.L., Kerton, F.M., Yan, N., 2014. Direct conversion of chitin into a N-containing furan derivative. Green Chem. 16 (4), 2204-2212.

Corma, A., Iborra, S., Velty, A., 2007. Chemical routes for the transformation of biomass into chemicals. Chem. Rev. 107 (6), 2411-2502.

Dorrestijn, E., Laarhoven, L.J.J., Arends, I.W.C.E., Mulder, P., 2000. The occurrence and reactivity of phenoxyl linkages in lignin and low rank coal. J. Anal. Appl. Pyrol. 54 (1-2), 153-192.

Dutta, P.K., Dutta, J., Tripathi, V.S., 2004. Chitin and chitosan: chemistry, properties and applications. J. Sci. Ind. Res 63 (1), 20-31.

Gao, Y., Zhang, J., Chen, X., Ma, D., Yan, N., 2014. A metal-free, carbon-based catalytic system for the oxidation of lignin model compounds and lignin. ChemPlusChem 79 (6), 825-834.

Ghosh, D., Roy, A., Seidel, R., Winter, B., Bradforth, S., Krylov, A.I., 2012. FirstPrinciple protocol for calculating ionization energies and redox potentials of solvated molecules and ions: theory and application to aqueous phenol and phenolate. J. Phys. Chem. B 116 (24), 7269-7280.

Harris, E.E., D'Ianni, J., Adkins, H., 1938. Reaction of hardwood lignin with hydrogen. J. Am. Chem. Soc. 60 (6), 1467-1470.

He, J., Zhao, C., Lercher, J.A., 2012. Ni-Catalyzed cleavage of aryl ethers in the aqueous phase. J. Am. Chem. Soc. 134 (51), 20768-20775.

Huber, G.W., Iborra, S., Corma, A., 2006. Synthesis of transportation fuels from biomass: chemistry, catalysts, and engineering. Chem. Rev. 106 (9), 4044-4098.

Keane, M.A., Patterson, P.M., 1996. Compensation behaviour in the hydrogenation of benzene, toluene and o-xylene over $\mathrm{Ni} / \mathrm{SiO} 2$. Determination of true activation energies. J. Chem. Soc. Faraday T. 92 (8), 1413-1421.

Kobayashi, H., Komanoya, T., Guha, S.K., Hara, K., Fukuoka, A., 2011. Conversion of cellulose into renewable chemicals by supported metal catalysis. Appl. Catal. A-Gen. 409-410 (0), 13-20.

Li, Z., Assary, R.S., Atesin, A.C., Curtiss, L.A., Marks, T.J., 2013. Rapid ether and alcohol $\mathrm{C}-\mathrm{O}$ bond hydrogenolysis catalyzed by tandem high-valent metal triflate + supported Pd catalysts. J. Am. Chem. Soc. 136 (1), 104-107.

Long, J., Li, X., Guo, B., Wang, F., Yu, Y., Wang, L., 2012. Simultaneous delignification and selective catalytic transformation of agricultural lignocellulose in cooperative ionic liquid pairs. Green Chem. 14 (7), 1935-1941.

Long, J., Li, X., Guo, B., Wang, L., Zhang, N., 2013. Catalytic delignification of sugarcane bagasse in the presence of acidic ionic liquids. Catal. Today 200 (0), 99-105. 
Mao, J.Z., Zhang, L.M., Xu, F., 2012. Fractional and structural characterization of alkaline lignins from carex meyeriana kunth. Cell. Chem. Technol. 46 (3-4), 193-205.

Marshall, A.L., Alaimo, P.J., 2010. Useful products from complex starting materials: common chemicals from biomass feedstocks. Chem. Eur. J. 16 (17), 4970-4980.

Matson, T.D., Barta, K., Iretskii, A.V., Ford, P.C., 2011. One-pot catalytic conversion of cellulose and of woody biomass solids to liquid fuels. J. Am. Chem. Soc. 133 (35), 14090-14097.

Mu, W., Ben, H., Ragauskas, A., Deng, Y., 2013. Lignin pyrolysis components and upgrading-technology review. BioEnerg. Res. 6 (4), 1183-1204.

Murat Sen, S., Henao, C.A., Braden, D.J., Dumesic, J.A., Maravelias, C.T., 2012 Catalytic conversion of lignocellulosic biomass to fuels: process development and technoeconomic evaluation. Chem. Eng. Sci. 67 (1), 57-67.

Nakagawa, Y., Tomishige, K., 2012. Production of 1,5-pentanediol from biomass via furfural and tetrahydrofurfuryl alcohol. Catal. Today 195 (1), 136-143.

Ngee, E.L.S., Gao, Y., Chen, X., Lee, T.M., Hu, Z., Zhao, D., Yan, N., 2014. Sulfated mesoporous niobium oxide catalyzed 5-hydroxymethylfurfural formation from sugars. Ind. Eng. Chem. Res. 53, 14225-14233.

Parthasarathi, R., Romero, R.A., Redondo, A., Gnanakaran, S., 2011. Theoretical study of the remarkably diverse linkages in lignin. J. Phys. Chem. Lett. 2 (20), 2660-2666.

Pepper, J.M., Fleming, R.W., 1978. Lignin and related compounds. V. The hydrogenolysis of aspen wood lignin using rhodium-on-charcoal as catalyst. Can. J. Chem. 56 (7), 896-898.

Pepper, J.M., Lee, Y.W., 1969. Lignin and related compounds. I. A comparative study of catalysts for lignin hydrogenolysis. Can. J. Chem. 47 (5), 723-727.

Pepper, J.M., Supathna, P., 1978. Lignin and related compounds. VI. A study of variables affecting the hydrogenolysis of spruce wood lignin using a rhodiumon-charcoal catalyst. Can. J. Chem. 56 (7), 899-902.

Perlack, R.D., 2005. Biomass as feedstock for a bioenergy and bioproducts industry the technical feasibility of a billion-ton annual supply. 〈http://www.ornl.gov/ $\sim$ webworks/cppr/y2001/rpt/123021.pdf/.

Pierson, Y., Chen, X., Bobbink, F.D., Zhang, J., Yan, N., 2014. Acid-Catalyzed chitin liquefaction in ethylene glycol. ACS Sustain. Chem. Eng. 2 (8), 2081-2089.

Prechtl, M.H.G., Scariot, M., Scholten, J.D., Machado, G., Teixeira, S.r.R., Dupont, J., 2008. Nanoscale $\mathrm{Ru}(0)$ particles: arene hydrogenation catalysts in imidazolium ionic liquids. Inorg. Chem. 47 (19), 8995-9001.

Ren, Y., Yan, M., Wang, J., Zhang, Z.C., Yao, K., 2013. Selective reductive cleavage of inert Aryl $\mathrm{C}_{3} \mathrm{O}$ bonds by an iron catalyst. Angew. Chem. Int. Edit. 52 (48), 12674-12678.

Ruppert, A.M., Weinberg, K., Palkovits, R., 2012. Hydrogenolysis goes bio: from carbohydrates and sugar alcohols to platform chemicals. Angew. Chem. Int. Edit. 51 (11), 2564-2601.

Sales, F.G., Maranhão, L.C.A., Filho, N.M.L., Abreu, C.A.M., 2007. Experimental evaluation and continuous catalytic process for fine aldehyde production from lignin. Chem. Eng. Sci. 62 (18-20), 5386-5391.

Sammons, R.J., Harper, D.P., Labbe, N., Bozell, J.J., Elder, T., Rials, T.G., 2013. Characterization of organosolv lignins using thermal and FT-IR spectroscopic analysis. BioResources 8 (2), 27162752-2767, 2716.

Sergeev, A.G., Hartwig, J.F., 2011. Selective, nickel-catalyzed hydrogenolysis of aryl ethers. Science 332 (6028), 439-443.
Sergeev, A.G., Webb, J.D., Hartwig, J.F., 2012. A heterogeneous nickel catalyst for the hydrogenolysis of aryl ethers without arene hydrogenation. J. Am. Chem. Soc. 134 (50), 20226-20229.

Siankevich, S., Fei, Z., Scopelliti, R., Laurenczy, G., Katsyuba, S., Yan, N., Dyson, P.J., 2014. Enhanced conversion of carbohydrates to the platform chemical 5hydroxymethylfurfural using designer ionic liquids. ChemSusChem 7 (6), 1647-1654.

Song, Q., Cai, J., Zhang, J., Yu, W., Wang, F., Xu, J., 2013. Hydrogenation and cleavage of the $\mathrm{C}-\mathrm{O}$ bonds in the lignin model compound phenethyl phenyl ether over a nickel-based catalyst. Chinese J. Catal. 34 (4), 651-658.

Song, Q., Wang, F., Cai, J., Wang, Y., Zhang, J., Yu, W., Xu, J., 2013. Lignin depolymerization (LDP) in alcohol over nickel-based catalysts via a fragmentation-hydrogenolysis process. Energ. Environ. Sci. 6 (3), 994-1007.

Song, Q., Wang, F., Xu, J., 2012. Hydrogenolysis of lignosulfonate into phenols over heterogeneous nickel catalysts. Chem. Commun. 48 (56), 7019-7021.

Stöcker, M., 2008. Biofuels and biomass-to-liquid fuels in the biorefinery: catalytic conversion of lignocellulosic biomass using porous materials. Angew. Chem. Int. Edit. 47 (48), 9200-9211.

Suni, Y.C., Weni, J.L., Xui, F., Suni, R.C., 2010. Fractional and structural characterization of organosolv and alkaline lignins from tamarix austromogoliac. Sci. Res. Essays 5 (24), 3850-3864.

Wang, X., Rinaldi, R., 2012. Solvent effects on the hydrogenolysis of diphenyl ether with raney nickel and their implications for the conversion of lignin. Chemsuschem 5 (8), 1455-1466.

Yabushita, M., Kobayashi, H., Fukuoka, A., 2014. Catalytic transformation of cellulose into platform chemicals. Appl. Catal. B-Environ. 145 (0), 1-9.

Yan, N., Dyson, P.J., 2013. Transformation of biomass via the selective hydrogenolysis of CO bonds by nanoscale metal catalysts. Curr. Opin. Chem. Eng. 2 (2), $178-183$.

Yan, N., Yuan, Y., Dykeman, R., Kou, Y., Dyson, P.J., 2010. Hydrodeoxygenation of lignin-derived phenols into alkanes by using nanoparticle catalysts combined with brønsted acidic ionic liquids. Angew. Chem. Int. Edit. 49 (32), 5549-5553.

Yan, N., Zhao, C., Dyson, P.J., Wang, C., Liu, L.T., Kou, Y., 2008. Selective degradation of wood lignin over noble-metal catalysts in a two-step process. ChemSusChem 1 (7), 626-629.

Younker, J.M., Beste, A., Buchanan, A.C., 2011. Computational study of bond dissociation enthalpies for substituted $\beta-0-4$ lignin model compounds. ChemPhysChem 12 (18), 3556-3565.

Zaheer, M., Hermannsdörfer, J., Kretschmer, W.P., Motz, G., Kempe, R., 2014. Robust heterogeneous nickel catalysts with tailored porosity for the selective hydrogenolysis of aryl ethers. ChemCatChem 6 (1), 91-95.

Zakzeski, J., Bruijnincx, P.C.A., Jongerius, A.L., Weckhuysen, B.M., 2010. The catalytic valorization of lignin for the production of renewable chemicals. Chem. Rev. 110 (6), 3552-3599.

Zhang, J., Asakura, H., Rijn, J.v., Yang, J., Duchesne, P., Zhang, B., Chen, X., Zhang, P., Saeys, M., Yan, N., 2014. Highly efficient, NiAu-catalyzed hydrogenolysis of lignin into phenolic chemicals. Green Chem. 16, 2432-2437.

Zhang, J., Teo, J., Chen, X., Asakura, H., Tanaka, T., Teramura, K., Yan, N., 2014 A series of $\mathrm{NiM}(M=\mathrm{Ru}, \mathrm{Rh}$, and $\mathrm{Pd})$ bimetallic catalysts for effective lignin hydrogenolysis in water. ACS Catal. 4, 1574-1583.

Zhang, J., Yuan, Y., Kilpin, K.J., Kou, Y., Dyson, P.J., Yan, N., 2013. Thermally responsive gold nanocatalysts based on a modified poly-vinylpyrrolidone. J. Mol. Catal. A-Chem. 371 (0), 29-35. 